\title{
KERJASAMA PENGEMBANGAN POTENSI WISATA SUNGAI DI DESA MENURAN KECAMATAN BAKI
}

\author{
Riana R. Dewi ${ }^{11}$, Siti Wulandari ${ }^{11}$, Arief Abdul Azis ${ }^{1)}$ \\ 1)Program Studi Akuntansi, Fakultas Ekonomi, Universitas Islam Batik Surakarta, Surakarta, Jawa Tengah, Indonesia \\ Corresponding author : Riana Rachmawati Dewi \\ E-mail : rianardewi1@gmail.com
}

\section{Diterima 22 Oktober 2020, Direvisi 02 November 2020, Disetujui 02 November 2020}

\begin{abstract}
ABSTRAK
Desa wisata merupakan kelompok masyarakat yang mampu berinteraktsi dan bekerjasama dalam pemberdayaan potensi yang ada. Penggunaaan dan pemanfaatan lahan sebagai lokasi desa wisata di wilayah Kec. Baki, Kab. Sukoharjo selalu dikembangkan. Tujuan dalam kegatan ini adalah membantu mengembangkan potensi wisata yang ada. Mitra adalah kelompok masyarakat Masdulkabi dan karang taruna di Desa Menuran Kecamatan Baki sebanyak 40 orang. Tim Himpunan Mahasiswa UNIBA Surakarta melakukan riset dan melihat adanya potensi wisata di sebuah Desa Menuran dengan Sungai sebagai kunci utama. Masalah yang dihadapi masih kurangnya pelatihan pemanfaatan teknologi, perbaikan sarana dan prasarana di sekitar lokasi. Metode yang dilakukan adalah pendekatan dan pengarahan kepada kelompok masyarakat melalui sosialisasi dan pelatihan serta perbaikan sarana dan prasarana dalam bentuk sarana sanitasi kesehatan dan pengadaan perahu wisata. Hasil dari program ini adalah Desa wisata sungai di Menuran yang masyarakatnya semakin kreatif dan pengelolaan potensi sungai tersebut sebagai wisata edukasi kepada masyarakat untuk memelihara dan menjaga sungai.
\end{abstract}

Kata kunci : potensi; lokal; sungai.

\begin{abstract}
A tourist village is a community group capable of interacting and collaborating in empowering existing potentials. Used of land as a tourist village location in the district. Baki, Kab. Sukoharjo is always being developed. The purpose of this activity is to help develop the existing tourism potential. Partners are the Masdulkabi community group and youth organizations in Menuran Village, Baki District, totaling 40 people. The UNIBA Surakarta Student Association team conducted research and saw the potential for tourism in a Menuran Village with rivers as the main key. The problem faced is still a lack of training in the use of technology, repair of facilities and infrastructure around the location. The method used is an approach and direction to community groups through socialization and training as well as repair of facilities and infrastructure in the form of health sanitation facilities and procurement of tourist boats. The result of this program is a river tourism village in Menuran whose people are getting more creative and managing the river's potential as an educational tour for the community to maintain and protect the river.
\end{abstract}

Keywords : potential; local; river

\section{PENDAHULUAN}

Kabupaten kabupaten terkecil kedua di Jawa Tengah yang terdiri dari 12 kecamatan, 17 kelurahan, dan 150 desa. Kecamatan baki sebagai salah satu kecamatan di Kabupaten Sukoharjo yang dikenal luas oleh masyarakat Kota Solo dan sekitarnya, terutama dalam kuliner nasi liwet dan sentra produsen/kerajinan gitar. Kecamatan ini terdiri dari 14 desa, yaitu : Desa Bakipandeyan, Bentakan, Duwet, Gedongan, Gentan, Jetis, Kadilangu, Kudu, Mancasan, Ngrombo, Purbayan, Siwal, Waru dan Desa Menuran. Dilihat dari penggunaan lahan di kecamatan Baki hanya sedikit yang digunakan sebagai lokasi desa wisata. Pemanfaatan pengelolaan ekonomi lebih digunakan di sektor UMKM (Sugiyarti, 2020)

Pariwisata memiliki beberapa bentuk yang salah satunya adalah pariwisata berbasis masyarakat(Tyas \& Damayanti, 2018) Pariwisata yang dikelola masyarakat lokal yang bertitik berat pada keberlanjutan lingkungan dapat digunakan untuk memahami dan mempelajari budaya lokal (Nurazizah \& Darsiharjo, 2018)

Desa wisata merupakan sebuah kawasan perdesaan yang memiliki beberapa karakteristik khusus/potensi tertentu yang dikelola menjadi daerah tujuan wisata 
(Yusmiono, Wisata, \& Batanghari, 2019). Ada beberapa macam desa wisata diantaranya desa berbasis wisata alam, berbasis sosialbudaya, maupun berbasis kuliner. sebagaimana yang diungkapkan (Astuti \& Issundari, 2016) Hasil intrepretasi di Desa Purbayan dan Desa Bentakan terdapat wahana air dan pemancingan yang merupakan bentuk lahan rekreasi. Sedangkan di Desa Menuran tepatnya disebelah utara terdapat sungai Baki yang bermuara di sungai Bengawan Solo. Pada titik tertentu sungai Baki terdapat sebuah taman yang bernama Taman MASDULKABI sekaligus obyek wisata air yang diresmikan pada bulan November 2018 lalu. Hal ini dapat terwujud dengan adanya gerakan Masyarakat Peduli Kali Baki (MASDULKABI) yang saat ini juga menjadi organisasi yang mengelola tempat tersebut. Kelompok masyarakat tersebut terdiri dari berbagai usia dan agama yang merasa kuatir dengan sungai yang kotor, banyaknya sampah baik daun kering tetapi juga sampah rumah tangga, daerah sekitar sungai yang kering dan adanya talud yang mulai jebol. Sebelum sungai tersebut dikelola dengan baik hanya sebagai tempat memancing ikan dan membuang sampah. Disaat musim hujan, air akan meluap dan apabila musim kemarau air Kelompok tersebut mulai mengelola sungai dan terlihat adanya sarana dan prasarana yang sudah diadakan yaitu lokasi untuk pemancingan, area bermain anak-anak, gubug untuk bersantai, kapal wisata untuk mengarungi sungai Baki, dan juga ada warung lokal dan beberapa jajanan kecil di sekitar sungai yang dijadikan sebagai taman. Lokasi taman yang menjadi ajang bermain anak dan bercengkerama keluarga dari masyarakat sekitar selalu diupayakan ada pengembangan untuk penambahan sarana dan prasarana. Pengelola memberikan ruang kepada masyarakat dan pihak lain untuk membantu dalam bentuk apapun demi pengembangan dan perluasan lokasi wisata yang sudah dikelola menjadi lebih bermanfaat (Arida et al., 2019) .

Disisi lain, perbaikan sarana dan prasarana sanitasi kesehatan menjadi penting karena masyarakat yang memanfaatkan taman untuk bermain atau sekedar menikmati suasana merasa kesulitan karena tidak adanya sarana toilet. Pada pertengahan tahun 2019 Masdulkabi sudah merencanakan membuat tempat pembuangan, toilet, sumur, gudang, menata dan mempercantik taman. Hal tersebut masih terkendala biaya karena masyarakat sangat selektif dalam menerima bantuan dari phak lain. Masalah yang dikemukakan dalam pengabdian ini adalah pengabdian kepada masyarakat yang dilakukan Dosen bersama mahasiswa dan pengelola Masdulkabi untuk berpartsipasi mengembangkan wisata sungai Baki.

\section{METODE}

Bentuk kegiatan yang didanai bagi mahasiswa dan Dosen pendamping dilakukan dalam bentuk pelatihan, pendampingan dan penambahan sarana dan prasarana wisata. Dibawah ini dalam bentuk tabel dijelaskan pelaksanaan kegiatan.

Tabel 1. Kegiatan yang dilaksanakan

\begin{tabular}{|c|c|c|}
\hline Kegiatan & Tujuan & Luaran \\
\hline Sosialisasi & $\begin{array}{l}\text { Dilakukan } \\
\text { kepada } \\
\text { kelompok } \\
\text { Masdulkabi } \\
\text { dan karang } \\
\text { taruna }\end{array}$ & Program kerja \\
\hline Pelatihan & $\begin{array}{l}\text { Karang taruna } \\
\text { sebagai } \\
\text { generasi muda } \\
\text { dapat } \\
\text { memanfaatkan } \\
\text { media } \\
\text { informasi untuk } \\
\text { mengenalkan } \\
\text { wisata sungai } \\
\text { Masdulkabi }\end{array}$ & $\begin{array}{c}\text { Media } \\
\text { informasi } \\
\text { untuk lebih } \\
\text { mengenalkan } \\
\text { Masdulkabi }\end{array}$ \\
\hline \multirow{2}{*}{$\begin{array}{l}\text { Perbaikan } \\
\text { dan } \\
\text { pengadaan } \\
\text { sarana } \\
\text { prasarana }\end{array}$} & $\begin{array}{l}\text { Pengadaan } \\
\text { saran sanitasi } \\
\text { Kesehatan }\end{array}$ & $\begin{array}{l}\text { Adanya } \\
\text { sarana } \\
\text { sanitasi }\end{array}$ \\
\hline & $\begin{array}{l}\text { Pengadaaan } \\
\text { sarana wisata }\end{array}$ & Kapal wisata \\
\hline Evaluasi & $\begin{array}{l}\text { Kesesuaian } \\
\text { perencanaan dan } \\
\text { realisasi dan } \\
\text { keberlanjutan }\end{array}$ & $\begin{array}{c}\text { Adanya } \\
\text { laporan hasil } \\
\text { kegiatan }\end{array}$ \\
\hline
\end{tabular}

Metode ini dilakukan oleh mahasiswa secara bersama-sama dengan kelompok Masdulkabi dan karang taruna sebanyak 40 orang. (Maruf, 2014) dimana kegiatan ekonomi dapat muncul adanya pengembangan suatu daerah. Tujuan dari kegiatan ini adalah membantu potensi yang dapat dikembangkan dengan dukungan dari masyarakat setempat. Kegiatan ini dilaksanakan di desa Menuran Kecamatan Baki atau di lokasi kegiatan tersebut dilaksanakan.

\section{HASIL DAN PEMBAHASAN}

Pada bab ini disampaikan :

1. Sosialisasi

Kegiatan ini dimulai dengan melakukan sosialisasi pada tanggal 21 Juni 2019 dengan mengundang kelompok masyarakat MASDULKABI untuk memaparkan teknis pelaksanaan 
kegiatan. Pada gambar 1 dan 2 dijelaskan bahwa sosialisasi dilakukan dalam 2 kelompok yaitu kelompok Masdulkabi dan karang taruna, dibedakan dalam kelompok masyarakat terutama karang taruna agar lebih memahami dan berpartisipasi aktif dalam mengembangkan potensi desa dan ide kreatif yang dapat dimunculkan.

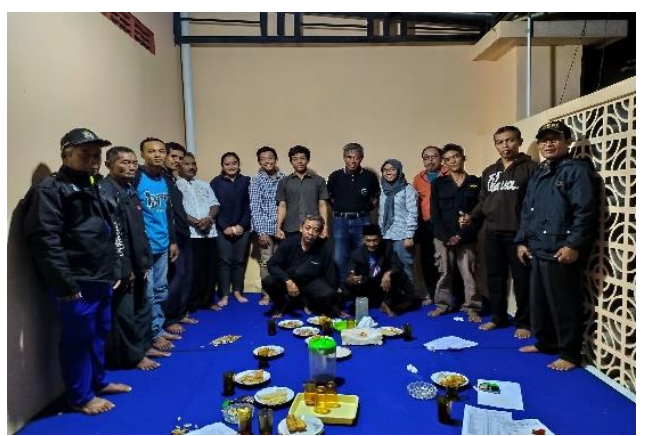

Gambar 1. Sosialisasi Kepada MASDULKABI

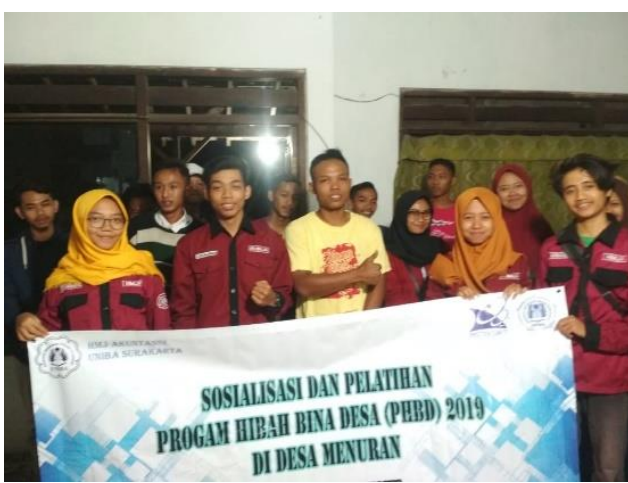

Gambar 2. Sosialisasi Kepada Pemuda Tunas Mekar

2. Pelatihan

Pelatihan lebih difokuskan pada karang taruna dalam memanfaatkan media informasi seperti instagram, twitter, facebook dengan tampilan yang menarik. Pada gambar 3 dibawah ini adalah hasil pelatihan di Karang Taruna yang saat pelatihan difokuskan di Balai Desa.

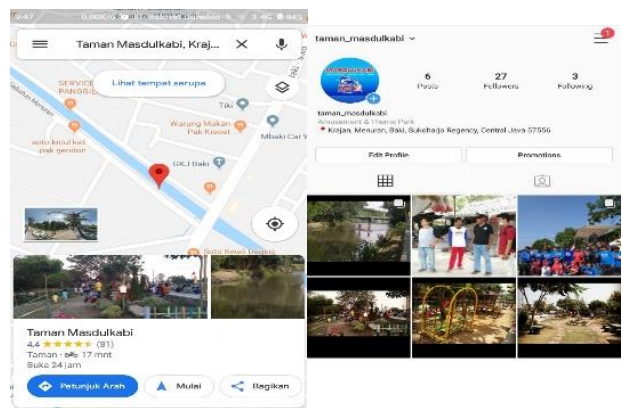

Gambar 3. Tampilan di media sosial
3. Perbaikan dan pengadaan sarana dan prasarana

a. Dimulai bulan Agustus sampai November 2019. Perbaikan fasilitas toilet. Dimulai dengan peletakan batu pertama pada tanggal 01 September 2019. Dalam pengadaan fasilitas toilet akhirnya digabung dengan pendanaan dari masyarakat untuk gudang. Pembangunan ini diselesaikan pada pertengahan November mengingat pembangunan tersebut bersifat gotong royong. Artinya tenaga kerja yang membangun fasilitas toilet, sumur dan gudang adalah sukarela dan disubsidi dari masyarakat Desa tersebut. Pembangunan sarana ini berada tepat di pinggir Kali Baki. Pada gambar 4 dijelaskan sebelum kegiatan dilaksanakan dan gambar 5 setelah bangunan fasilitas diadakan.

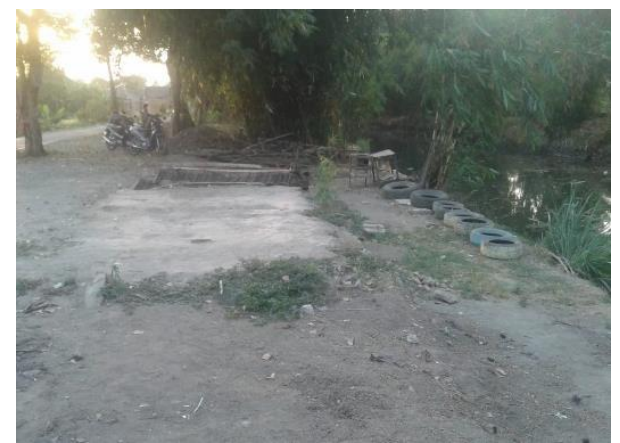

Gambar 4. Lahan sebelum di bangun toilet, sumur dan gudang

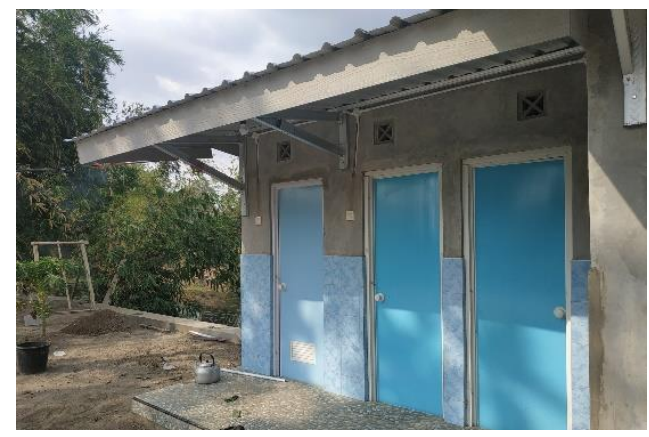

Gambar 5. Hasil Pembangunan toilet, sumur dan gudang

b. Pengadaan fasilitas perahu wisata

Dimulai berdiskusi dengan kelompok Masdulkabi saat sosialisasi atas model perahu wisata yang diharapkan. Pada tanggal 30 Agustus 2019 tim melakukan pemesanan perahu wisata ke salah satu masyarakat sekitar desa tersebut. Team mendasarkan pada wiraswasta Desa tersebut untuk membantu 
menghidupkan perekonomian juga di masyarakat sekitar. Gambar 6 merupakan lokasi dan perahu yang dibeli dari dana PHBD.

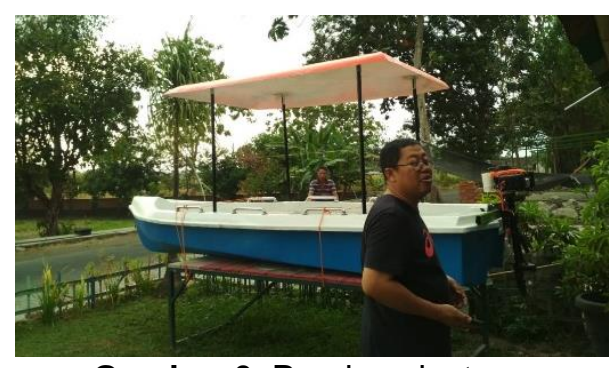

Gambar 6. Perahu wisata MASDULKABI

4. Evaluasi

Evaluasi dilakukan oleh Dosen pendamping kepada tim mahasiswa PHBD dan kelompok Masdulkabi di bulan Oktober 2019.

Tim monev dari Dikti juga melakukan evaluasi dengan mengundang tim PHBD UNIBA Surakarta untuk presentasi dan kunjungan ke Desa Menuran pada November 2019. Hasil evaluasi dinyatakan baik dan ada upaya keberlanjutan dan pemeliharaan oleh masyarakat setempat. Kelompok Masdulkabi selaku pengelola wisata Kali Baki . Pengelola tidak memungut biaya untuk masyarakat yang akan menikmati berkunjung tetapi khusus untuk perahu dipungut biaya $\mathrm{Rp}$. 2.000 ,- per orang untuk perawatan.
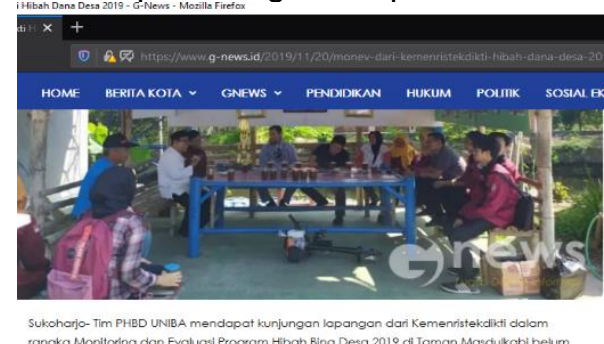

rangka Mo
lama ini.

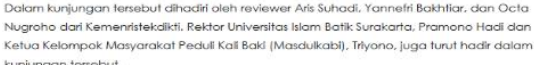

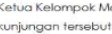

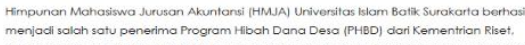

Gambar 7. Liputan di media massa

Peliputan di media massa seperti yang tampak pada Gambar 7 juga dilakukan untuk memberikan informasi dan edukasi kepada pembaca, dimana sungai apabila dikelola dengan baik oleh masyarakat setempat yang peduli terhadap lingkungan akan menjadi lahan perekonomian yang nantinya dapat memberikan kontribusi pendanaan kepada wlayah tersebut (Mulya \& Yudana, 2018).

\section{SIMPULAN DAN SARAN}

Dari hasil pelaksanaan kegiatan PHBD atas bimbingan kelompok masyarakat dalam pembangunan dan pengembangan potensi wisata di sungai Baki yang dilakukan oleh Dosen Akuntansi sebanyak 2 orang dan tim HMJ Akuntansi UNIBA Surakarta yang dimulai dari bulan Juli sampai dengan Desember dapat diberikan kesimpulan bahwa potensi desa yang di kelola dengan baik oleh masyarakatnya sendiri secara tidak langsung dapat menumbuhkan perekonomian. Potensi sungai yang sudah dikembangkan sebelumnya oleh masyarakat sekitar dalam bentuk pemeliharaan dapat digunakan sebagai wisata edukasi kepada generasi muda agar selalu memelihara sungai dan air sebagai sumber kehidupan (Pasirsurenpalabuhanratu, 2018). Hal ini sejalan dengan adanya pengelolaan potensi wilayah seharusnya dapat berjalan beriringan dengan pemberdayaan masyarakat

yang ada di sekitarnya (Yusmiono et al., 2019). Desa yang memiliki tempat wisata diharapkan dapat ikut menyumbang ekonomi dan menghidupkan perekonomian di sekitarnya (Ratu \& Adikampana, 2016).

\section{DAFTAR RUJUKAN}

Arida, N. S., Pujani, K., Studi, P., Pariwisata, D., Pariwisata, F., Udayana, U., ... Bali, P. (2019). KAJIAN PENYUSUNAN KRITERIA-KRITERIA DESA WISATA SEBAGAI INSTRUMEN. 17(1), 1-9.

Astuti, M., \& Issundari, S. (2016). Desa wisata sebagai aset soft power Indonesia. Masyarakat, Kebudayaan Dan Politik, 29(2),

64. https://doi.org/10.20473/mkp.v29i2201 6.64-74

Maruf, et all. (2014). Pengukuran Daya Saing Klaster Batik , Konveksi. BENEFIT Jurnal Manajemen Dan Bisnis, (9), 116. Retrieved from ournals.ums.ac.id/index.php/benefit/art icle/view/4172

Mulya, Q. P., \& Yudana, G. (2018). Analisis Pengembangan Potensi Kawasan Wisata Sungai Musi Sebagai Tujuan Wisata Di Kota Palembang. Cakra Wisata, 19(2), 41-54.

Nurazizah, G. R., \& Darsiharjo. (2018). Kesiapan Masyarakat Desa Wisata di Kampung Seni... 103. Gea Jurnal Pendidikan Geografi, 18(2), 103-113.

Pasirsurenpalabuhanratu, D. I. D. (2018). 
POTENSI ALAM SUNGAI CITARIK HILIR SEBAGAI WISATA MINAT KHUSUS RAFTING THE DEVELOPMENT OF NATURAL POTENTIAL OF RAFTING CITARIK RIVER AS A TOURISM INTEREST IN PASIRSUREN VILLAGE PALABUHANRATU. 4, 78-89.

Ratu, C., \& Adikampana, I. M. (2016). Strategi Pemasaran Desa Wisata Blimbingsari Kabupaten Jembrana. Jurnal Destinasi Pariwisata, 4(1), 60. https://doi.org/10.24843/jdepar.2016.v 04.i01.p10

Sugiyarti, S. R. (2020). P- ISSN : 2550-0171 Pemberdayaan Masyarakat Pengrajin Gitar di Desa Mancasan , Baki, Research Fair Unisri 2019 Pendahuluan Empowerment atau pemberdayaan masyarakat dapat dipahami sebagai suatu proses mengarahkan tidak masyarakat yang berdaya (powerless . 4(1).

Tyas, N. W., \& Damayanti, M. (2018). Potensi Pengembangan Desa Kliwonan sebagai Desa Wisata Batik di Kabupaten Sragen. Journal of Regional and Rural Development Planning, 2(1), 74. https://doi.org/10.29244/jp2wd.2018.2. 1.74-89

Yusmiono, B. A., Wisata, O., \& Batanghari, S. (2019). Analisis Potensi Pengembangan Objek Wisata Sungai Batanghari. 90-99. 